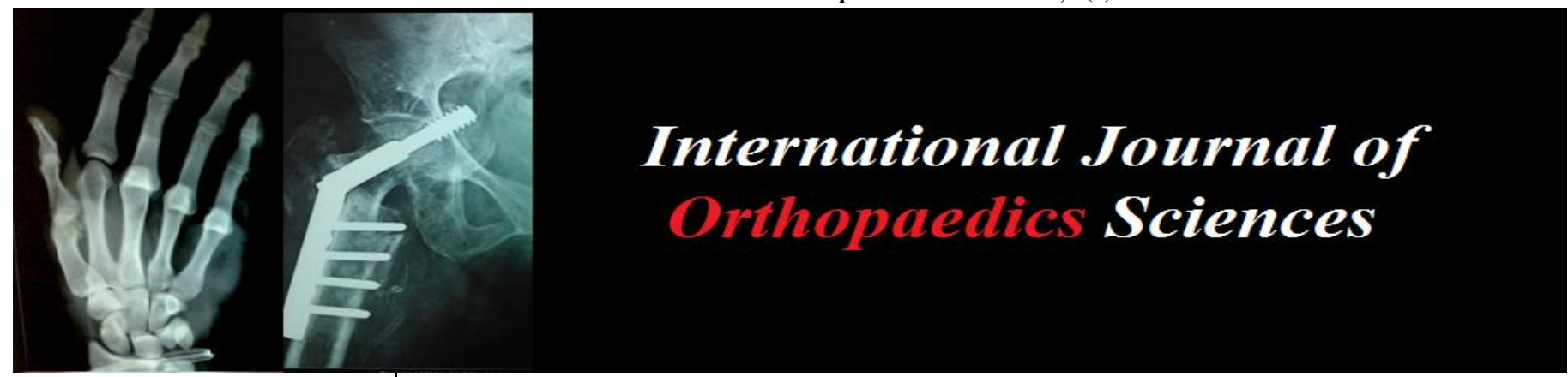

E-ISSN: 2395-1958

P-ISSN: 2706-6630

IJOS 2019; 5(4): 629-631

(C) 2019 IJOS

www.orthopaper.com

Received: 17-08-2019

Accepted: 21-09-2019

Dr. Thundathil Gangadharan Sreejith

Associate Professor, Department of Orthopedics, K.M.C.T.

Medical College, Calicut, Kerala, India

Kooranplankudy Tintu

Kunjumon

Junior Resident, Department of Orthopedics, K.M.C.T. Medical College, Calicut, Kerala, India
Corresponding Author: Dr. Thundathil Gangadharan Sreejith

Associate Professor, Department of Orthopedics, K.M.C.T Medical College, Calicut, Kerala, India

\section{An Indian study on analysis of outcome of middle 1/3rd fracture of clavicle treated by open reduction and internal fixation using locking compression plates: A prospective}

\section{Dr. Thundathil Gangadharan Sreejith and Kooranplankudy Tintu Kunjumon}

\author{
DOI: https://doi.org/10.22271/ortho.2019.v5.i4k.1744
}

\section{Abstract}

Clavicle fracture accounts to $4 \%$ of all fractures and $44 \%$ of fractures of the shoulder girdle. 1, 2, 3 During initial times clavicle fracture was managed conservatively using sling or figure of 8 brace. Traditionally even displaced mid 1/3rd shaft of clavicle fractures were treated conservatively. 4 Furthermore, there is some evidence that conservative management affects the outcome in terms of upper limb function and that treatment of non-unions produces inferior results. 5 clavicle fracture was classified based on Allman classification of which group 1-middle 1/3rd clavicle fracture accounts for $80 \%$ of all clavicle fractures.6 Recent studies have shown that open reduction with internal fixation with $3.5 \mathrm{~mm}$ LCP gives better result when compared to conservative management in displaced mid-shaft clavicle fracture. 7, 8 the main advantage of open reduction and internal fixation is early return to daily activities and decreased in pain when compared to conservative management in displaced middle $1 / 3$ rd clavicle fractures.9,10 All operated patients were examined for maturation of surgical scar, cosmetic appearance, radiological union and range of movements of shoulder. It was found that $90 \%$ of fracture united uneventfully. In 3\% patients delayed union was noted, infected non-union in 3\% cases, neurological deficit in $3 \%$ cases and $1 \%$ patients had implant failure due to screw back out of non-locked screws.

This study gives us a message that all middle 1/3rd fracture fixed by LCP provide quite excellent functional and radiological outcome, which is now a days considered as treatment of choice.

Keywords: Middle 1/3rd clavicle fracture, open reduction with LCP

\section{Introduction}

As an orthopedic surgeon clavicle fracture is one among the most common fracture's which we seen in our op and ED. And it accounts for around four percentage of all fractures of shoulder girdle. Among this middle one third clavicle fracture accounts around eighty percentage; about 12 to 15 percentage are laterally localized and rest affect middle one third Calvicle. Recent literature has highlighted the high non-union rate in the displaced mid-shaft clavicle fractures, with a non-union rate up to $15 \%$. Surgery should be considered for open fractures, compromised skin conditions, neurological deficiencies, vascular injury, ipsilateral rib fracture or floating shoulder. The location and type of fracture is important in decision making, as it influences management strategies. Operative treatments, commonly used are open reduction and internal fixation (ORIF) using plates and screws as implants.

\section{Materials and Methods}

Prospective study of 180 patients in Kmct Medical College, a tertiary care hospital in Kerala, India for a period of thirty-six months. Study was conducted on patients of age group between 15 to 60 years with middle one third clavicle fracture reporting to above hospital. Patients with pathological fracture, acromioclavicular joint subluxation excluded from study.

All operated patients were followed up at regular interval results were statically analyzed All operated patients were followed up at regular interval results were statically analyzed using statistical package for social sciences (SPSS)20.2 software

\section{Results and Conclusions}

All operated patients were examined for maturation of surgical scar, cosmetic appearance, 
radiological union and range of movements of shoulder. It was found that $90 \%$ of fracture united un- eventfully. In 3\% patients delayed union was noted, infected non-union in $3 \%$ cases, neurological deficit in $3 \%$ cases and $1 \%$ patients had implant failure due to screw back out of non-locked screws.

\section{Discussion}

Since ancient times clavicle fractures were treated by conservative measures (figure of 8 bandage, cuff $n$ collar sling, local bone setting etc).Most common problem of nonoperative treatment were pain and disability during first two to three weeks. The patient may not be able to carry out his vocations partially or fully during the above period, also there is an unreported higher prevalence of non-union and cosmetic disfigurement as an unacceptable outcome of conservative care for the above fracture. The recent trend towards operative treatment is to tackle the above mentioned issues and to offer better comfort for the patient with the above fracture. Nonunion rate as high as $33 \%$ is reported for displaced fractures if treated conservatively and come down to $03 \%$ if operated and fixed with plates and screws.

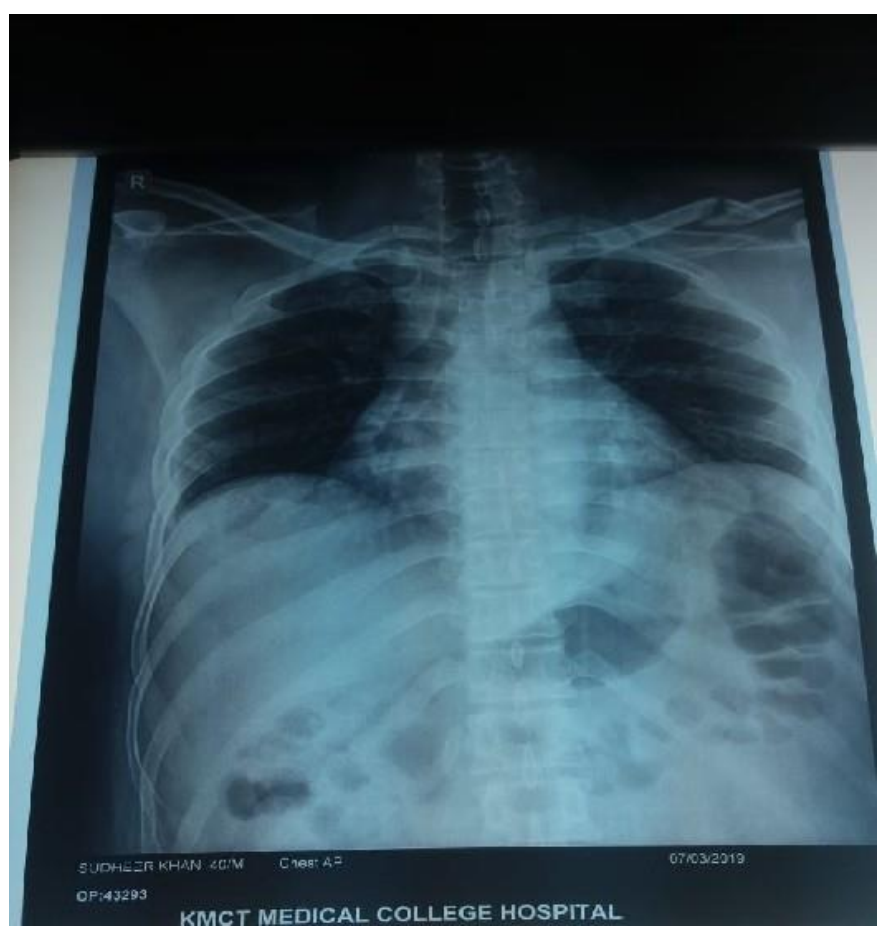

Fig 1: Preoperative x-ray of left middle 1/3rd clavicle fracture

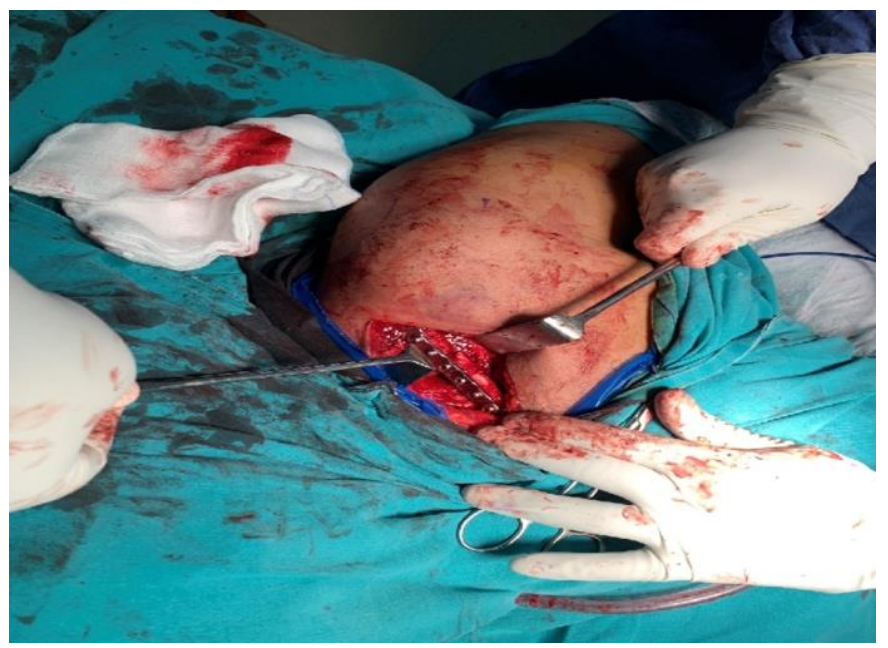

Fig 2: intraoperative fixation of middle 1/3rd clavicle fracture left fixed using $3.5 \mathrm{~mm} \mathrm{LCP}$

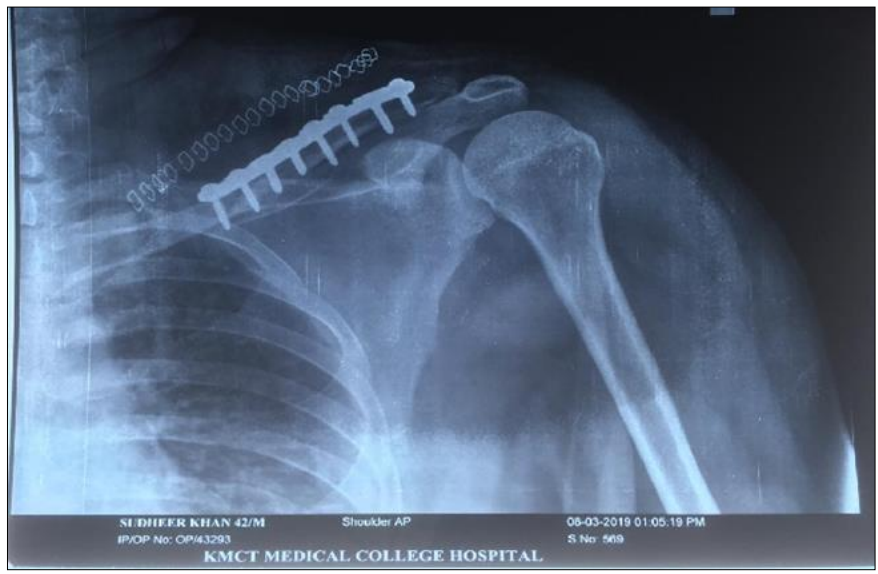

Fig 3: Post op x-ray showing open reduction and internal fixation with $3.5 \mathrm{~mm}$ LCP for middle $1 / 3$ rd clavicle left

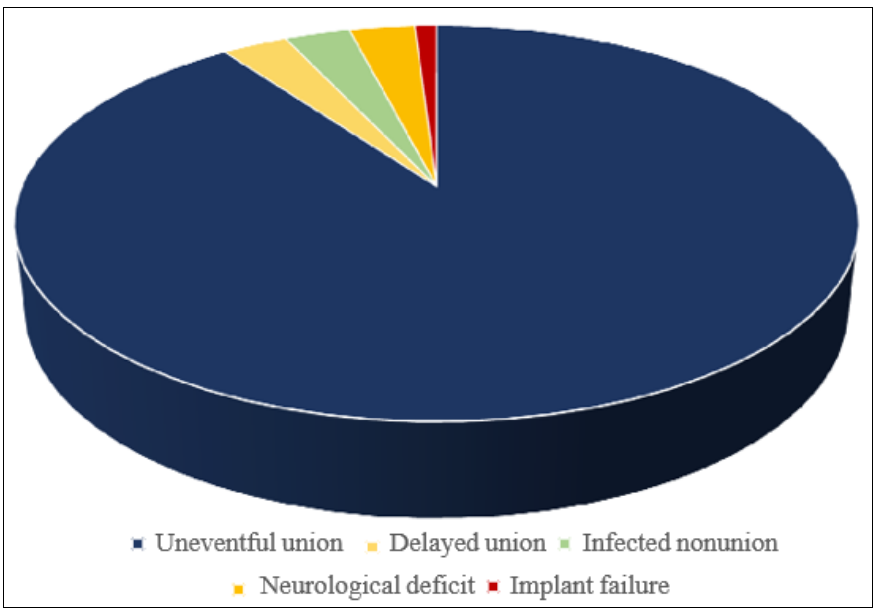

Fig 4: Show the different of uneventful delayed infected neurological and implant

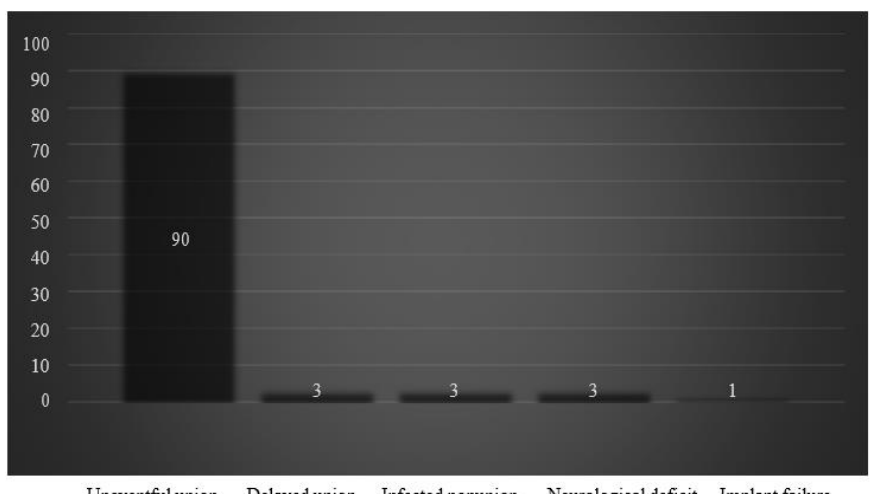

\section{Conclusion}

This study gives us a message that all middle 1/3rd fracture fixed by LCP provide quite excellent functional and radiological outcome, which is now a days considered as treatment of choice.

\section{References}

1. Lenza M, Belloti JC, Gomes Dos Santos JB, Matsumoto MH, Faloppa F. Surgical interventions for treating acute fractures or non-union of the middle third of the clavicle. Cochrane database of systematic reviews (Online). 2009; 4:CD007428.

2. Nowak J, Mallmin H, Larsson S. The Aetiology and epidemiology of Clavicular fractures. A prospective study during a two-year period in Uppsala, Sweden. Injury. 2000; 31(5):353-358. 
3. Bravo CJ, Wright CA. Displaced, comminuted diaphyseal clavicle fracture. The Journal of hand surgery. 2009; 34(10):1883-1885.

4. Nowak J, Holgersson M, Larsson S. Can we predict longterm Sequelae after fractures of the clavicle based on initial findings? A prospective study with nine to ten years of follow-up. Journal of shoulder and elbow surgery/American Shoulder and Elbow Surgeons et al. 2004; 13(5):479-486.

5. Lenza M, Belloti JC, Andriolo RB, Gomes Dos Santos JB, Faloppa F. Conservative interventions for treating middle third clavicle fractures in adolescents and adults. Cochrane database of systematic reviews (Online), 2009, CD007121.

6. Robert Bucholez, James D Heckman, Charles CourtBrown, Rockwood Green's Fractures In Adults Volume 1, 6th Ed. Lippincott Williams and Wilkins, 2006, 12131216.

7. Canadian Orthopaedic Trauma Society. Non operative treatment compared with plate fixation of displaced mid shaft Clavicular fractures. A multicenter randomized clinical trial. J Bone Joint Surg Am. 2007; 89(1):1-10

8. Huang JI, Toogood P, Chen MR, Wilber JH, Cooperman DR. Clavicular anatomy and the applicability of precontoured plates. J Bone Joint Surg Am. 2007; 89:2260-5

9. Wg Cdr V Kulshrestha, Primary Plating Of Displaced Mid-Shaft Clavicular Fractures. MJAFI. 2008; 64:208211.

10. Byron Chaldis, Nick Sachinis, Efthimios Samolodas, Christos Dimitriou, Anastasios Christodoulu, John Pournaras. Acute management of clavicular fracture: A long term functional outcome study. Acta Orthop Belg. 2008; 74:303-307. 